This is the post-print i.e. final accepted version of the paper https://doi.org/10.1016/i.nanoen.2020.104495

\title{
23.5\%-efficient silicon heterojunction silicon solar cell using molybdenum oxide as hole-selective contact
}

\author{
Julie Dréon*, Quentin Jeangros, Jean Cattin, Jan Haschke, Luca Antognini, Christophe Ballif and Mathieu Boccard
}

Photovoltaics and Thin-Film Electronics Laboratory (PV-lab), Institute of Microengineering (IMT), École Polytechnique Fédérale de Lausanne (EPFL), Rue de la Maladière 71b, CH-2002 Neuchâtel, Switzerland.

*Corresponding author: julie.dreon@epfl.ch

Keywords: solar cell, silicon heterojunction, molybdenum oxide, carrier-selective contacts, dopant free, thickness variation

\begin{abstract}
Interest in silicon heterojunction solar cells is growing due to their manufacturing simplicity and record efficiencies. However, a significant limitation of these devices still stems from parasitic light absorption in the amorphous silicon layers. This can be mitigated by replacing the traditional $(p)$ and $(n)$ doped amorphous silicon selective layers by other materials. While promising results have been achieved using molybdenum oxide $\left(\mathrm{MoO}_{\mathrm{x}}\right)$ as a front-side hole-selective layer, charge transport mechanisms in that contact stack have remained elusive and device efficiencies below predictions. We carefully analyze the influence of the $\mathrm{MoO}_{x}$ and intrinsic a-Si:H thicknesses on current-voltage properties and discuss transport and performance-loss mechanisms. In particular, we find that thinning down the $\mathrm{MoO}_{\mathrm{x}}$ and (i)a-Si:H layers (down to $4 \mathrm{~nm}$ and $6 \mathrm{~nm}$ respectively) mitigates parasitic optical sub-bandgap $\mathrm{MoO}_{\mathrm{x}}$ absorption and drastically enhances charge transport, while still providing excellent passivation and selectivity. High-resolution transmission microscopy reveals that such thin $\mathrm{MoO}_{x}$ layer remains continuous and close to a $\mathrm{MoO}_{3}$ stoichiometry in spite of the reactive sputtering and annealing steps involved in the electrode deposition. A screen-printed device reaching a certified efficiency of $23.5 \%$ and a fill factor of $81.8 \%$ is demonstrated, bridging the gap with traditional Si-based contacts and demonstrating that dopant-free selective contacts can rival traditional approaches.
\end{abstract}

\section{Introduction}

The interest in silicon heterojunction (SHJ) is growing in the field of photovoltaics due to the simplicity of their structure and processing, as well as the high efficiencies that can be achieved [1], [2]. The record efficiency for a silicon single junction is currently held by a SHJ combined with an interdigitated back contacted (IBC) design, reaching $26.7 \%$ [3], [4]. Most of the SHJs use stacks of intrinsic and doped hydrogenated amorphous silicon (a-Si:H) as passivating and carrier-selective layers [5]. These stacks provide good surface passivation and selectivity thanks to the high hydrogen content of these layers and dopability of amorphous silicon, respectively [1], [6]-[8].

However, the excellent passivation performance of this contact architecture often comes at the expense of carrier transport in comparison with solar cells based on silicon homojunctions which translate into fill factor (FF) losses. This effect stems from the lower conductivity of doped a-Si:H compared to crystalline silicon, band offsets between these two crystalline phases [9][10], and the formation of an opposing Schottky contact between a-Si:H and the transparent conductive oxide (TCO) [11]-[13]. In addition, the use of a-Si:H (bandgap of $\sim 1.7 \mathrm{eV}$ ) on the light-incoming side of the device leads to parasitic absorption below $500 \mathrm{~nm}$ [1], [14]. Photons that are parasitically absorbed in the intrinsic a-Si:H ((i)a-Si:H) can partly contribute the cell's short circuit current density $\left(\mathrm{J}_{\mathrm{sc}}\right)$, but photons absorbed in the doped a-Si:H layer are lost
[14], [15]. This typically causes a $\mathrm{J}_{\mathrm{sc}}$ loss of up to $2.1 \mathrm{~mA} \mathrm{~cm}^{-2}$ compared to the one of a cell with an ideal cell front-side [15]. One investigated strategy to overcome this parasitic absorption is to replace the intrinsic and p-type (i/p)a-Si:H layers by more transparent carrier selective contacts. Siliconbased materials (in their nanocrystalline phase and/or alloyed with carbon and oxygen) [16]-[21], and transition metal oxides (TMOs) [22]-[27] are the most widely followed approaches, alongside a few other organic and inorganic materials [28], [29].

Most efficient devices using non-Si contacts have been achieved with molybdenum oxide $\left(\mathrm{MoO}_{\mathrm{x}}\right)$ as hole-selective contact [30]-[32]. This 3.0-eV-bandgap material substitutes p-type a-Si:H on the light-incoming side of the solar cell to reduce parasitic absorption at short wavelengths [23], [26], [30], [33]-[35]. The high workfunction of $\mathrm{MoO}_{x}$ (5.7 eV to 6.9 eV [22], [26], [33], [36], [37]) enables this n-type semiconductor to ensure hole selectivity for a silicon absorber. Yet it does not provide sufficient surface passivation when deposited directly on c-Si [38]. An (i)a-Si:H layer is thus usually inserted as sketched in Fig 1 a.
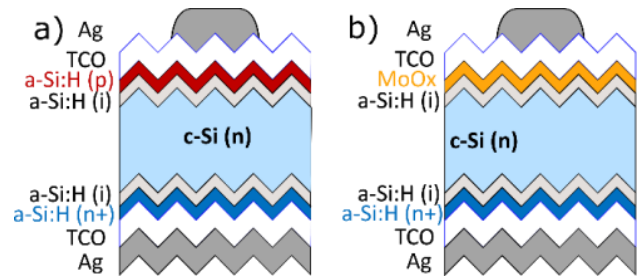

Figure 1: a) standard SHJ and b) MoOx-based cell schema 
As for standard SHJ devices (see Fig. 1b), a transparent electrode is required to provide lateral transport of charges on the positive-electrode side. A remarkable $22.5 \%$-efficient device (with an FF of $80 \%$ ) was demonstrated in 2015 using a combination of (i)a-Si:H, $\mathrm{MoO}_{\mathrm{x}}$, hydrogen-doped indium oxide and a copper-plated grid [30]. Efficiency and FF were on par with those of standard SHJ state-of-the art values at the time [39].

However, there are still challenges when contacting c-Si with a (i)a-Si:H/MoOx/TCO stack. First, a strong degradation of hole extraction, characterized by an FF drop, occurs upon annealing above $130{ }^{\circ} \mathrm{C}$, a temperature required to cure industrial screen-printing pastes. Such degradation was attributed to the formation of an interlayer between $\mathrm{MoO}_{x}$ and TCO [30], the formation of $\mathrm{SiO}_{x}$ at the $\mathrm{MoO}_{x} / \mathrm{a}-\mathrm{Si}: \mathrm{H}$ interface [40], or/and the reduction of $\mathrm{MoO}_{\mathrm{x}}$ by $\mathrm{H}$ effusing from adjacent layers leading to a decrease of its workfunction [41]. The latter could be successfully mitigated by reducing the $\mathrm{H}$-content of the a-Si:H layer prior to $\mathrm{MoO}_{\mathrm{x}}$ deposition, improving efficiency by $2 \%$ absolute yet without reaching similar performances as bestin-class devices [41].

Second, sub-bandgap absorption in the $\mathrm{MoO}_{\mathrm{x}}$-based contact stack hampers its transparency and thus its advantage over standard (p)a-Si:H [30], [40]. Reducing the $\mathrm{MoO}_{x}$ thickness is therefore a promising strategy, especially since TMOs have been reported to better protect (i)a-Si:H layers from damage induced by TCO sputtering compared to (p)a-Si:H [40], [42][45]. However, since electrical transport in the $\mathrm{MoO}_{x}$ layer is carried by electrons through defect states, the $\mathrm{MoO}_{\mathrm{x}} /(\mathrm{i}) \mathrm{a}-\mathrm{Si}: \mathrm{H}$ interface is expected to be more recombining than the (p)a$\mathrm{Si}: \mathrm{H} /(\mathrm{i}) \mathrm{a}-\mathrm{Si}: \mathrm{H}$ one. This could affect passivation, and call for a thicker (i)a-Si:H layer than when using a (p)a-Si:H contact.

Following these considerations, we vary here the thicknesses of the (i)a-Si: $\mathrm{H}$ and $\mathrm{MoO}_{x}$ layers in $\mathrm{SHJ}$ devices and discuss their influence on the optical and electrical performance of the cell. Furthermore, a low temperature curing paste is employed to avoid degradation and to assess the potential of this contact strategy using state-of-the-art SHJ processing [41], [46].

\section{Experimental details}

Fig. 2 details the processing sequence followed here. We used nine 180- $\mu \mathrm{m}$-thick $\mathrm{n}$-type textured float zone wafers with a resistivity of 1.7-2.3 $\Omega \mathrm{cm}$. A stack composed of (i)a-Si:H

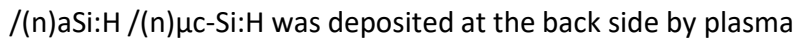
enhanced chemical vapor deposition (PECVD) at $200^{\circ} \mathrm{C}$ on all wafers. Three different thicknesses ${ }^{1}(6 \mathrm{~nm}, 8 \mathrm{~nm}$ and $10 \mathrm{~nm})$ of (i)a-Si:H were then deposited on the front side of the wafers (three co-processed wafers per thickness). Annealing in air at $250{ }^{\circ} \mathrm{C}$ during $20 \mathrm{~min}$, prior to $\mathrm{MoO}_{\mathrm{x}}$ deposition, was then performed in an oven ("pre-annealing" step [41]) to reduce the hydrogen content in the front-side (i)a-Si:H layer. The preannealing step was shown to induce no detectable thickness variation by ellipsometry. After removal of the surface oxide in an aqueous solution of $1 \%$ diluted hydrofluoridric acid (HF), a 4-nm-, 8-nm- or 9-nm-thick $\mathrm{MoO}_{x}$ layer was thermally evaporated on the front side, each time on three wafers with a different (i)a-Si:H thickness. $\mathrm{MoO}_{\mathrm{x}}$ evaporation was done in a vacuum chamber (base pressure before deposition $\sim 4^{*} 10^{-6} \mathrm{mbar}$ ) from stoichiometric $\mathrm{MoO}_{3}$ powder at a deposition rate of about $0.03 \mathrm{~nm} / \mathrm{s}$. Finally, indium tin oxide (ITO) was sputtered on the front $(70 \mathrm{~nm})$ through a mask to form five $2 \times 2 \mathrm{~cm}^{2}$ devices per wafer. ITO (150 nm) and Ag $(100 \mathrm{~nm})$ were then sputtered over the full back side area. For these steps, only wafers with the same $\mathrm{MoO}_{x}$ thickness (thus three wafers each time) were co-processed. A silver grid was finally screen-printed on the front side using a lowtemperature paste, cured at $130{ }^{\circ} \mathrm{C}$. In the front metallization design, busbars define the perimeter of the cells and are excluded from the measurement area.

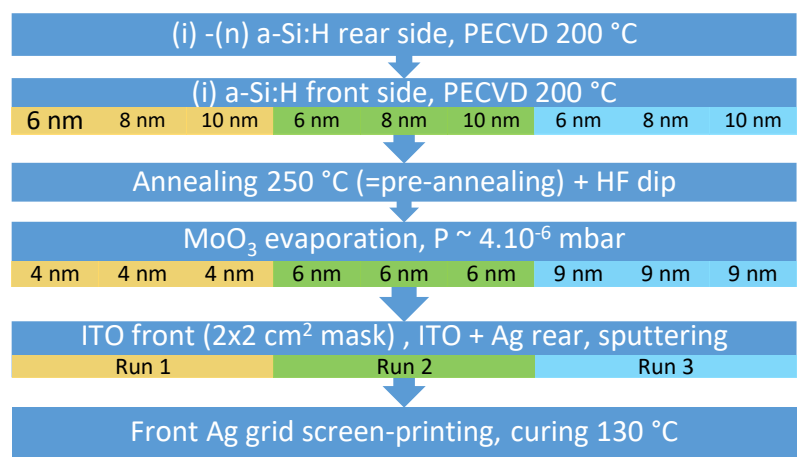

Figure 2: Process flow

Standard SHJ solar cells were processed as references, using the same rear side stack, a 6-nm-thick (i)a-Si:H layer on the front side capped with an 8-nm-thick PECVD (p)a-Si:H layer instead of evaporated $\mathrm{MoO}_{\mathrm{x}}$, omitting the pre-annealing step since it is useful to avoid $\mathrm{H}$ effusion in MoOx only, and as it generally leads to a slight passivation degradation. Standard screen-printing $\mathrm{Ag}$ paste cured at $210^{\circ} \mathrm{C}$ was used.

The structure and chemistry of the contact was assessed by transmission electron microscopy (TEM). For that purpose, a layer stack of (i)a-Si:H/MoO $/$ /TTO was deposited on a <111>oriented mechanically polished (n)c-Si wafer. After annealing at $130{ }^{\circ} \mathrm{C}$ for 30 minutes, mimicking curing of the low temperature paste, a thicker $\mathrm{MoO}_{\mathrm{x}}$ layer (of $20 \mathrm{~nm}$ ) was deposited on top of ITO to serve as a freshly evaporated $\mathrm{MoO}_{x}$ reference. The contact stack was finalized by sputtering a $\mathrm{Ag}$ layer. A thin lamella was prepared using the conventional focused ion beam lift-out technique with a final thinning voltage of $2 \mathrm{kV}$ in a Zeiss Nvision 40. Scanning TEM (STEM) high-angle annular dark-field (HAADF) images and energy-

\footnotetext{
${ }^{1}$ All thicknesses are given on textured surfaces, calculated from measurements on flat $\mathrm{Si}$ or glass divided by a ratio of 1.5 accounting for the pyramids geometry.
} 
dispersive X-ray spectroscopy maps were recorded in a FEI Titan Themis microscope operated at $200 \mathrm{kV}$ with a beam current of $200 \mathrm{pA}$. Electron energy-loss spectra (EELS) were acquired at $80 \mathrm{kV}$ and at cryogenic temperature $\left(-165^{\circ} \mathrm{C}\right)$ to assess the oxidation states of the thin $(4 \mathrm{~nm})$ and thick $(20 \mathrm{~nm})$ $\mathrm{MoO}_{\mathrm{x}}$ layers without introducing electron beam artifacts [47]. A convergence semi-angle of $30.5 \mathrm{mrad}$ was employed, while the collection semi-angle was $47 \mathrm{mrad}$. A dispersion of 0.1 $\mathrm{eV} /$ channel was employed for the dual EELS scans. For comparison purposes, $\mathrm{M} 3$ edges were aligned and rescaled to a value of 1 after removing the conventional power law background (using data within the ranges $380-390 \mathrm{eV}$ and 445$450 \mathrm{eV}$ to fit the background). Experimental data was compared to the reference $\mathrm{MoO}_{2}$ and $\mathrm{MoO}_{3}$ EELS spectra of [47] to assess the oxidation state of $\mathrm{MoO}_{x}$ as a function of its thickness and processing history.

\section{Results and discussion}

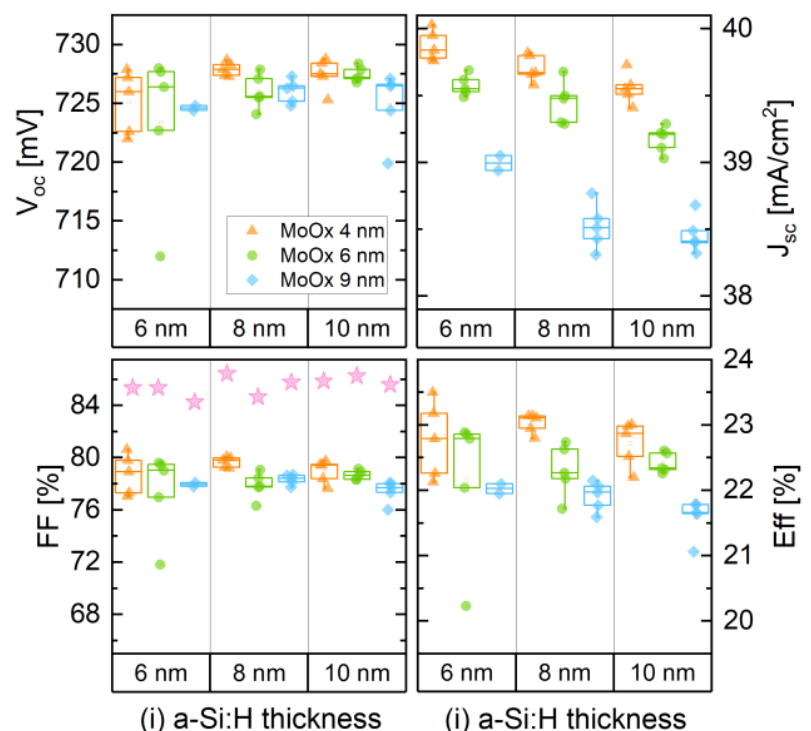

Figure 3: a) Voc, b) $\mathrm{J}_{\mathrm{sc}}, \mathrm{c}$ ) FF, d) Efficiency of MoOx-based solar cells with different thicknesses for the front (i)a-Si:H and $\mathrm{MoO}_{x}$ layers. Each dot represents one of five cells on a wafer. One wafer was prepared per condition. The pink stars represent the pseudo FF extracted from the Suns Voc measurements.

Fig. 3 shows the parameters extracted from J-V measurements of the devices with different (i)a-Si:H and $\mathrm{MoO}_{x}$ thicknesses. The measurements were done with a designed black mask shading the external edges of the cell and the entire inactive area of the wafer. The open circuit voltage $\left(\mathrm{V}_{\text {oc }}\right)$ values in Fig. 3a are similar for all $\mathrm{MoO}_{x}$ and (i)a-Si:H thicknesses. Yet, statistical analysis indicates a statistically relevant $\mathrm{V}_{\text {oc }}$ gain upon thickening the (i)a-Si:H layer of $0.61 \pm 0.27 \mathrm{mV} / \mathrm{nm}$ (see Supporting Information about statistical analysis) and a $\mathrm{V}_{\mathrm{oc}}$ loss of $-0.41 \pm 0.25 \mathrm{mV} / \mathrm{nm}$ when changing the $\mathrm{MoO}_{\mathrm{x}}$ thickness, but in that case, statistical analysis suggests the trend is less clear. No correlation between the two thicknesses influence on $\mathrm{V}_{\mathrm{oc}}$ is observed. The thinnest $\mathrm{MoO}_{\mathrm{x}}$ thus globally yields a $\mathrm{V}_{\mathrm{oc}} \sim 2 \mathrm{mV}$ higher than for the thickest layers. Part of this gain $(0.6 \mathrm{mV})$ can be attributed to the photogeneration difference, as estimated using a one-diode model with $J_{s c}$ shown in Fig. $3 \mathrm{~b}$ as the photogenerated current, but photoluminescence imaging (Fig. S1 in Supporting Information) and high illumination $\mathrm{V}_{\mathrm{oc}}$ measurements (Fig. S2) [8] suggest that the thinnest $\mathrm{MoO}_{\mathrm{x}}$ also provides better passivation and selectivity than thicker films (discussed in Supporting Information). This demonstrates that the $4 \mathrm{~nm}$ $\mathrm{MoO}_{\mathrm{x}}$ film is sufficiently thick to protect the passivation provided by the (i)a-Si:H layer from sputtering damage and maintains sufficient selectivity to efficiently extract holes.

Fig. $3 b$ shows that $J_{s c}$ decreases when thickening either the $\mathrm{MoO}_{\mathrm{x}}$ or (i)a-Si:H layer. The optical loss induced by $\mathrm{MoO}_{\mathrm{x}}(0.25$ $\pm 0.01 \mathrm{~mA} \mathrm{~cm}^{-2}$ per $\mathrm{nm}$ of $\mathrm{MoO}_{\mathrm{x}}$ thickness, irrespective of the (i)a-Si:H thickness in the range tested) is higher than that induced by (i)a-Si:H $\left(0.10 \pm 0.01 \mathrm{~mA} \mathrm{~cm}{ }^{-2}\right.$ per $\mathrm{nm}$ of a-Si:H, irrespective of the $\mathrm{MoO}_{\mathrm{x}}$ thickness, and as reported in Ref. [15]).

To identify more accurately the origin of these losses, external quantum efficiency (EQE) and reflectance measurements are shown in Fig. 4 and Table 1, highlighting gains in $\mathrm{J}_{\mathrm{sc}}$ compared to the reference ( $p$ )a-Si:H SHJ cell. Reflectance is similar for all $\mathrm{MoO}_{\mathrm{x}}$ devices, with the exception of a slight variation in the 400-600 $\mathrm{nm}$ range, which may originate from batch-to-batch ITO variations. From Fig. $4 \mathrm{a}$, the (i)a-Si:H thickness influences absorption mostly for wavelengths below $600 \mathrm{~nm}$, and has no effect on reflection. On the other hand, Fig. $4 b$ shows that the use of $\mathrm{MoO}_{\mathrm{x}}$ influences absorption over the whole wavelength range. Noticeably, the EQE signal is reduced from $600 \mathrm{~nm}$ to $1200 \mathrm{~nm}$ when increasing the $\mathrm{MoO}_{\mathrm{x}}$ thickness. This is due to sub-bandgap parasitic absorption in this range, as previously observed in Refs. [30], [40]. The fact that this effect occurs in the visible range may also explain why $\mathrm{MoO}_{\mathrm{x}}$ sub-bandgap absorption impacts the $\mathrm{J}_{\text {sc }}$ more strongly than (i)a-Si:H UV-blue absorption, as the photon flux is lower in the UV. In our study, a J $\mathrm{sc}_{\mathrm{sc}}$ loss of $0.4 \mathrm{~mA} \mathrm{~cm}^{-2}$ in the $600-900 \mathrm{~nm}$ range is recorded for the thickest $\mathrm{MoO}_{x}$, but interestingly no loss is observed for the thinnest $\mathrm{MoO}_{\mathrm{x}}$. An internal quantum efficiency comparison in Fig. S3 yet suggests that sub-bandgap parasitical absorption is still slightly present for this film. In the $320-600 \mathrm{~nm}$ range, gains in $\mathrm{J}_{\mathrm{sc}}$ vary from 0.5 to $0.8 \mathrm{mAcm}$ 2 depending on the $\mathrm{MoO}_{\mathrm{x}}$ thickness (see Table 1 ). Although larger $\mathrm{J}_{\mathrm{sc}}$ gains compared to standard $\mathrm{SHJ}$ cells were reported in literature in this range $\left(1.9 \mathrm{~mA} \mathrm{~cm}^{-2}\right.$ in [34], $1.3 \mathrm{~mA} \mathrm{~m}^{-2}$ in [23], and $0.9 \mathrm{~mA} \mathrm{~cm}^{-2}$ in [30]), these gains were mitigated by a strong loss at longer wavelengths, reducing the overall $\mathrm{J}_{\mathrm{sc}}$ gain. In Ref. [34], the replacement of ITO by more transparent IO:H presumably compensated losses associated with sub-bandgap absorption in the $\mathrm{MoO}_{x}$ layer. Overall, cells featuring the thinnest $\mathrm{MoO}_{x}$ film investigated in this study exhibit a $\mathrm{J}_{\mathrm{sc}}$ gain of $1.3 \mathrm{~mA} \mathrm{~cm}^{-2}$. These results demonstrate that an adequate 
device architecture enables to fully benefit from the improved transparency of $\mathrm{MoO}_{\mathrm{x}}$ compared to (p)a-Si:H.

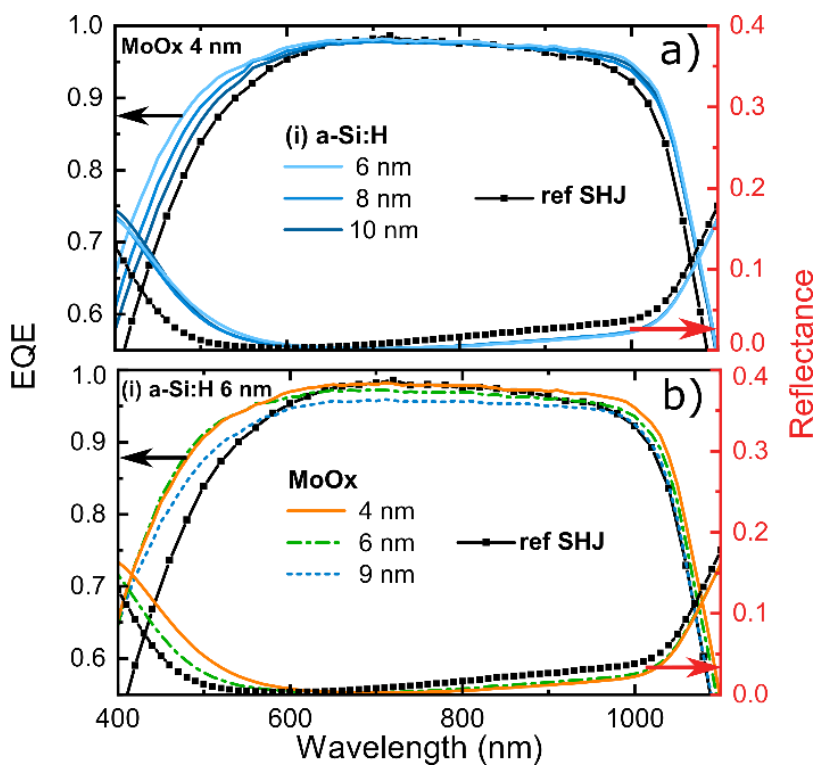

Figure 4: EQE and reflectance of a) devices with $4 \mathrm{~nm} \mathrm{MoOx}$ and variable (i)a-Si:H thickness; b) devices with $6 \mathrm{~nm}$ (i)a-Si:H and variable $\mathrm{MoO}_{\mathrm{x}}$ thickness.

\begin{tabular}{|c|c|c|c|c|}
\hline \multirow{2}{*}{$\begin{array}{l}\text { Samples with } \\
\text { thinnest (i)a-Si:H } \\
(6 \mathrm{~nm})\end{array}$} & \multicolumn{4}{|c|}{$\mathrm{J}_{\mathrm{sc}}$ gain or loss $\left(\mathrm{mA} / \mathrm{cm}^{2}\right)$} \\
\hline & $\begin{array}{l}320 \text { to } \\
600 \mathrm{~nm}\end{array}$ & $\begin{array}{l}600 \text { to } \\
900 \mathrm{~nm}\end{array}$ & $\begin{array}{l}900 \text { to } \\
1180 \mathrm{~nm}\end{array}$ & Total \\
\hline $\mathrm{MoO}_{x} 4 \mathrm{~nm}$ & 0.84 & 0.03 & 0.46 & 1.33 \\
\hline $\mathrm{MoO}_{x} 6 \mathrm{~nm}$ & 0.83 & -0.16 & 0.27 & 0.94 \\
\hline $\mathrm{MoO}_{\mathrm{x}} 9 \mathrm{~nm}$ & 0.53 & -0.43 & 0.05 & 0.15 \\
\hline
\end{tabular}

Table 1: $J_{\text {sc }}$ gain for MoOx-based cells compared to the reference $\mathrm{SHJ}$ cell over various wavelength ranges calculated from EQE curves.

Fig. $3 c$ shows that the thinnest layers investigated here are sufficient to ensure efficient charge extraction and passivation as a $\mathrm{FF}$ of up to $81 \%$ is achieved for the thinnest combination of MoOx and (i)a-Si:H layers. Statistical analysis indicates a stronger influence of the MoOx thickness, with a FF loss of -0.3 $\pm 0.1 \% / \mathrm{nm}$ and no significant impact from the (i)a-Si:H thickness. In the case of a standard SHJ with (p)a-Si:H, the (i)a$\mathrm{Si}: \mathrm{H}$ thickness affects the FF significantly [15], suggesting that the $\mathrm{MoO}_{x}$ layer imposes stronger selectivity than the (p)a-Si:H one. Indeed, if $\mathrm{MoO}_{\mathrm{x}}$ is more selective (thanks to its higher workfunction compared to (p)a-Si:H [23]), the hole population in (i)a-Si:H would be larger, which should lower the FF dependency on (i)a-Si:H thickness.

For standard SHJ solar cells, it is reported that an increase in (p)a-Si:H thickness leads to a higher FF [13], [15], [48], which might be due to the screening effect provided by the (p)a-Si:H layer thickness ("screening length") towards the reverse Schottky diode induced at the interface ITO/(p)a-Si:H due to work function mismatch [13]. The same trend for FF was observed by increasing the p-type layer doping [49]. Increasing the $\mathrm{MoO}_{\mathrm{x}}$ thickness, however, leads to a drop in $\mathrm{FF}$, which suggest that $\mathrm{MoO}_{x}$ contact behaves differently. This might be due to its n-type character, preventing the formation of a Schottky contact with ITO (as is the case with (p)a-Si:H which is depleted due to the workfunction mismatch between the (p)-type a-Si:H and the (n)-type ITO). This FF drop is linked to an increase of the cell series resistance $\left(R_{s}\right)$, notably due to the thicker MoOx film (Fig. S4). On glass samples with 8-nm substoichiometric $\mathrm{MoO}_{x}$, we measured a resistivity of $4.5 * 10^{4} \Omega$ $\mathrm{cm}$ after evaporation, and $300 \Omega \mathrm{cm}$ after annealing at $180^{\circ} \mathrm{C}$, literature values span from $200 \Omega \mathrm{cm}$ [50] to $5^{*} 10^{4} \Omega \mathrm{cm}$ [51]. This leads to an increase of $0.005 \mathrm{R}_{\mathrm{s}} / 1 \mathrm{~nm} \mathrm{MoO}$ (taking a MoOx resistivity of $4.5^{*} 10^{4} \Omega \mathrm{cm}$ ), which is too low to explain the FF decrease. This confirms other studies suggesting that transport is not only limited by ohmic losses only in this kind of contact [52].

All these cells showed remarkable stability after 11 months of unencapsulated storage in air with less than $1 \mathrm{mV}$ change in Voc and FF fluctuation within $+/-1 \%$ (see data in SI, Fig. S5).

Fig. 5 shows the J-V plots of cells with different $\mathrm{MoO}_{x}$ thicknesses. We observe a non-linear characteristic, usually referred to as "s-shape," which is typical for solar cells with unoptimized passivating contacts. This effect arises when the extraction rate of majority carriers of the contact becomes limited at this contact, or when the leakage rate of these carriers at the opposite contact is not negligible [53]. Although thinning down the $\mathrm{MoO}_{x}$ layer mitigates this effect, it is still present in the thinnest layer as evidenced by the lower current at high forward voltages compared to the reference SHJ. The impact on cell performance is however small, as the reference $\mathrm{SHJ}$ and the thinnest $\mathrm{MoO}_{\mathrm{x}}$ cells (orange) have a similar characteristic in the fourth quadrant. The higher $\mathrm{J}_{\mathrm{sc}}$ of the cells with a thin $\mathrm{MoO}_{x}$ leads to a higher efficiency compared to the reference $\mathrm{SHJ}$ cell.

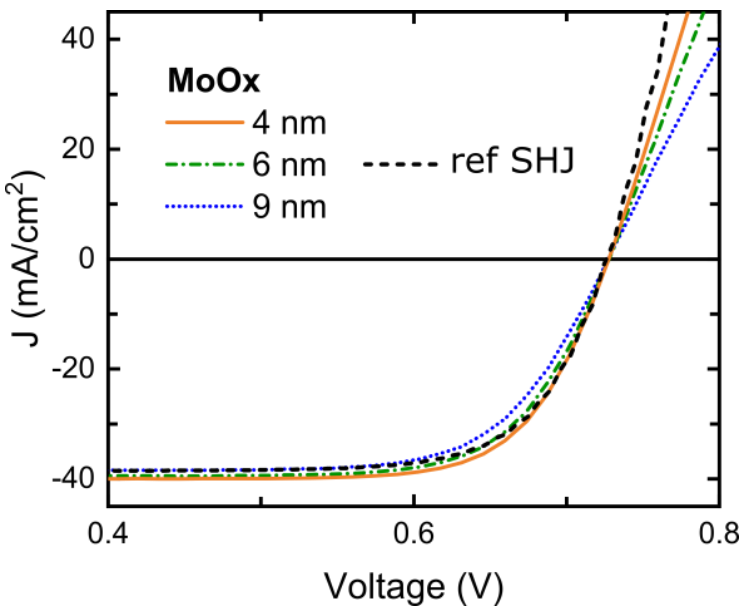

Figure 5: J-V of the three different cells featuring different MoOx thicknesses, with $6 \mathrm{~nm}$ of (i)a-Si:H for all devices. The dashed black line represents the reference SHJ cell ((p) a-Si:H of $8 \mathrm{~nm}$, (i) a-Si:H of $6 \mathrm{~nm}$ ). 
The microstructural and chemical properties of $\mathrm{MoO}_{x}$ were investigated by STEM HAADF imaging and EDX, as shown in Fig. $6 a-c$, to check $\mathrm{MoO}_{\mathrm{x}}$ contact oxidation state and aspect in the device. The EDX line profile shown in Fig. $6 \mathrm{c}$ highlights the presence of a thin amorphous $\mathrm{SiO}_{x}$ layer at the (i)a-Si:H/MoO interface, as reported in [40]. This layer is too thick (more than $2 \mathrm{~nm}$ ) to be attributed to a native oxide prior to $\mathrm{MoO}_{\mathrm{x}}$ deposition since an $\mathrm{HF}$ dip is included in the process around 20 min before samples loading in evaporator vacuum chamber. layer is comparable to the one of the thicker reference $\mathrm{MoO}_{x}$ layer ( 20-nm-thick) that was not subject to any annealing or plasma exposure (Fig. 6d-f). These $\mathrm{MoO}_{x}$ EELS spectra indicate The Mo M3-M2 EELS fine structure of the thin $\mathrm{MoO}_{\mathrm{x}}$ contact

that the layers have a stoichiometry closer to $\mathrm{MoO}_{3}$ than $\mathrm{MoO}_{2}$, even for a layer as thin as $4 \mathrm{~nm}$ and sandwiched between a-Si:H and ITO and subjected to annealing at $130{ }^{\circ} \mathrm{C}$ which could reduce it by hydrogen effusion from the a-Si: $\mathrm{H}$ layer. Either the $\mathrm{MoO}_{\mathrm{x}}$ stoichiometry is indeed unchanged (compared to the substoichiometric $\mathrm{MoO}_{\mathrm{x}}$ reference) by its surroundings, or the higher affinity of $\mathrm{Si}$ to Mo does result in a $\mathrm{MoO}_{\mathrm{x}}$ reduction after deposition (leading to the observed interfacial $\mathrm{SiO}_{\mathrm{x}}$ layer), which is cancelled by the subsequent plasma exposure during ITO deposition which could induce its re-oxidation. The main conclusion we can draw from this study is that the thin $4 \mathrm{~nm}$ MoOx embed in the contact stack has an oxidation state similar to the thick reference one.
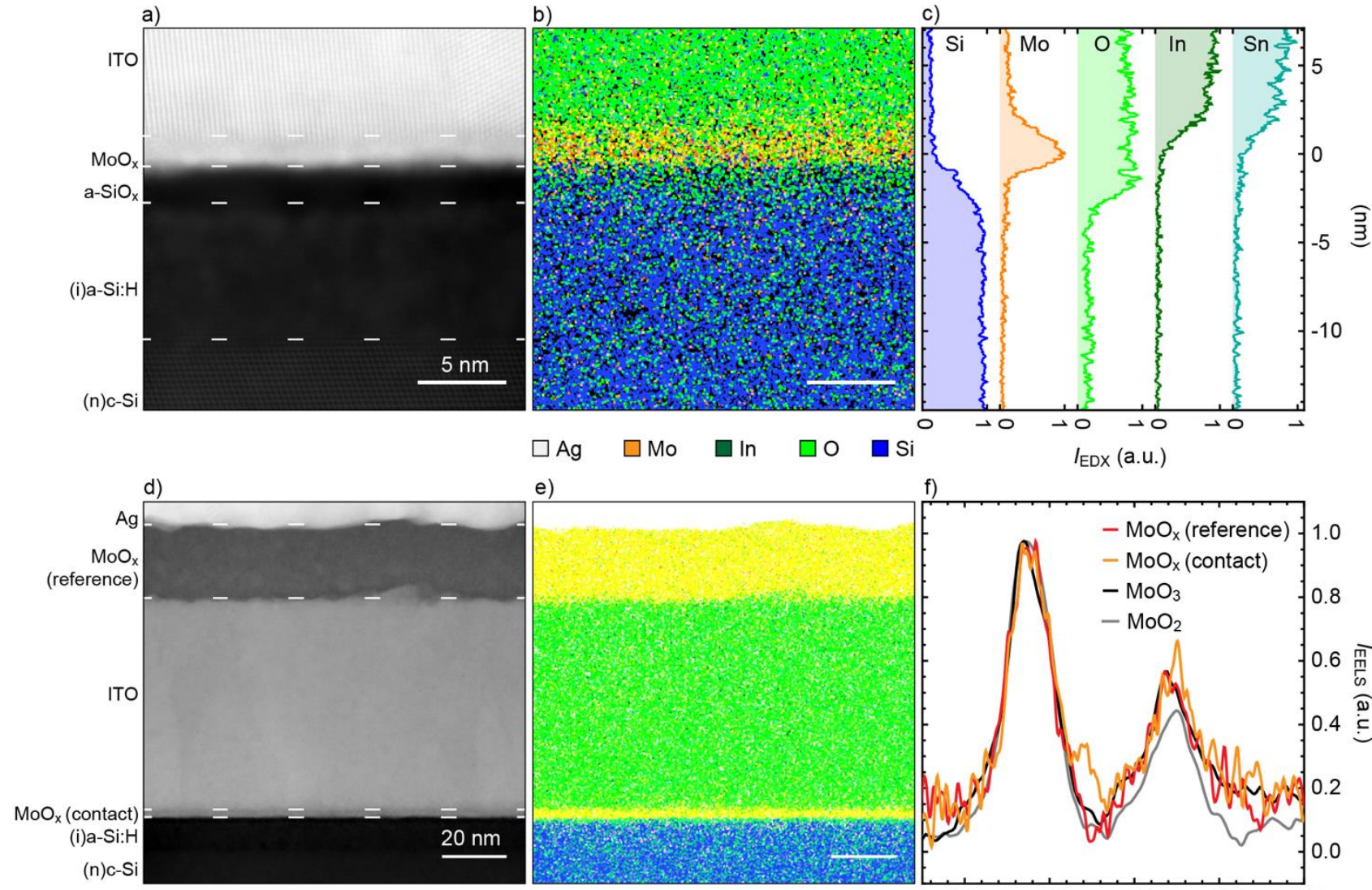

e)

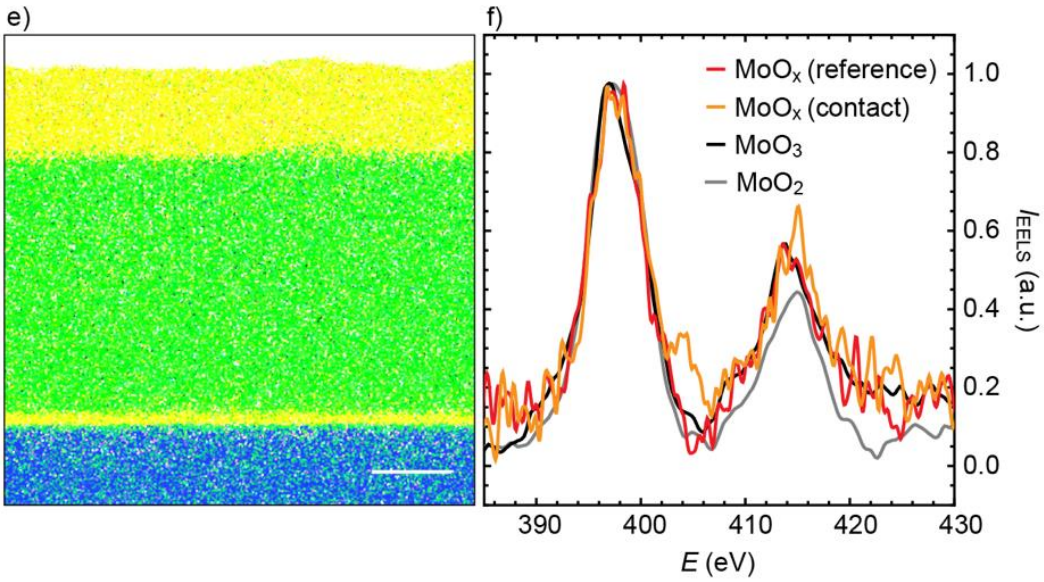

Figure 6: a) STEM HAADF image of the (i)a-Si:H/MoO $/$ /ITO contact deposited on a <111>-oriented (n)c-Si wafer, b) corresponding EDX map and c) background-subtracted EDX line profiles of the Si K, O K, In L, Sn L edges. d) STEM HAADF image of the contact coated with an as-deposited $\mathrm{MoO}_{\mathrm{x}}$ layer/Ag stack, e) corresponding EDX map and f) EELS Mo M3-M2 edges of the thin and thick MoO layers compared to reference spectra. 


\section{Optimized $\mathrm{MoO}_{\mathrm{x}}$ contact design for record performance}

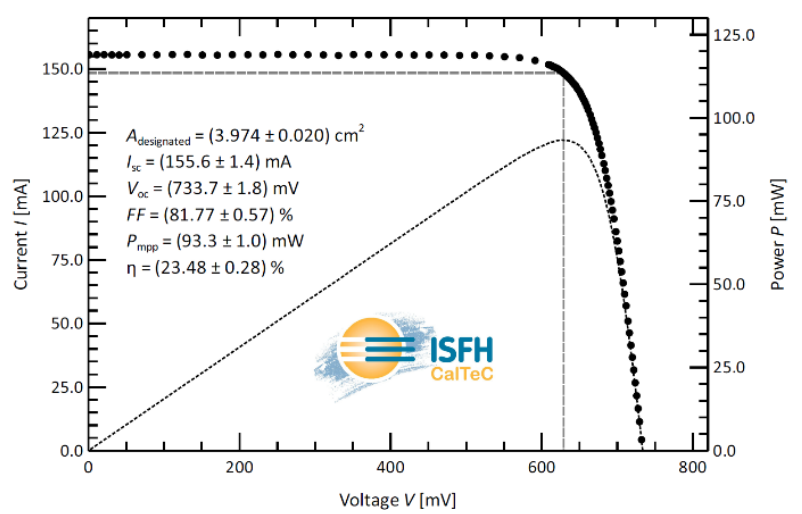

Fig. 8: certified J-V and power plots of the best $\mathrm{MoO}_{\mathrm{x}}$-based cell processed in the lab (certified by ISFH)

The highest efficiency of this series was obtained for a 4-nmthick $\mathrm{MoO}_{x}$ layer and a 6-nm-thick (i)a-Si:H film. Given that results with the thinnest (i)a-Si:H are quite spread, we processed another 4-nm MoOx cells with thicker (i)a-Si:H layer of $8 \mathrm{~nm}$, and a obtained a certified efficiency of $23.5 \%$ (Fig. 8), with a remarkable FF close to $82 \%$. This record efficiency for such solar cell was obtained without any masking step or photolithography and used a low-temperature Ag screenprinted metallization, causing $3 \%$ shadowing [46], [54].

The $39.15 \mathrm{~mA} / \mathrm{cm}^{2}$ current density reached for this record device is significantly below the $44.1 \mathrm{~mA} / \mathrm{cm}^{2}$ Lambertian limit for a $180-\mu \mathrm{m}$-thick silicon wafer. Using the analytical model presented in Ref [55], we estimate that the measured Jsc could be improved by $0.8 \mathrm{~mA} / \mathrm{cm}^{2}$ by suppressing all absorption in the $\mathrm{MoO}_{\mathrm{x}}$ layer and by another $0.8 \mathrm{~mA} / \mathrm{cm}^{2}$ by suppressing all absorption in the front (i)aSi:H layer. Another $0.8 \mathrm{~mA} / \mathrm{cm}^{2}$ and $1.2 \mathrm{~mA} / \mathrm{cm}^{2}$ could be gained by suppressing primary reflection and grid shading, respectively. About $1.2 \mathrm{~mA} / \mathrm{cm}^{2}$ could be recovered from parasitic absorption in the other layers (front ITO and rear ITO and $\mathrm{Ag}$ ), and $0.2 \mathrm{~mA} / \mathrm{cm}^{2}$ from improving light trapping.

\section{Conclusion}

In summary, we studied the influence of the thicknesses of the $\mathrm{MoO}_{\mathrm{x}}$ and (i)a-Si:H films used as hole contacts in SHJs. The thinnest layers studied here $\left(\sim 4 \mathrm{~nm}\right.$ and $\sim 6 \mathrm{~nm}$ for $\mathrm{MoO}_{\mathrm{x}}$ and (i)a-Si:H, respectively) resulted in best device performances, highlighting that such thin contact stacks enable simultaneously high selectivity, passivation, and good charge carrier transport. Thicker layers were found to lead to higher series resistance or charge carrier selectivity losses, without any strong correlation between the two. The device employing the thinnest $\mathrm{MoO}_{x}$ showed a higher optical response (higher $E Q E)$ than the reference ( $p$ )a-Si:H-based SHJ over the whole wavelength range (320-1180 nm). This gain in photocurrent of $1.3 \mathrm{~mA} / \mathrm{cm}^{2}$ resulted from mitigation in parasitic absorption losses. High-resolution transmission electron microscopy imaging and electron energy-loss spectroscopy revealed that the 4-nm-thick evaporated $\mathrm{MoO}_{\mathrm{x}}$ layer is continuous and has a stoichiometry close to $\mathrm{MoO}_{3}$, even after sputtering the overlaying ITO layer and annealing the contact stack. Overall, the high $J_{s c}$ allowed by this contact stack enabled the demonstration of a $23.5 \%$-efficient device, highlighting that $\mathrm{MoO}_{\mathrm{x}}$ is an excellent hole contact for c-Si heterojunctions. By reaching a similar efficiency to that of best SHJs cells produced in our laboratory [56], this study demonstrates that $\mathrm{MoO}_{x}$ can rival traditional contacting schemes in spite of its lower level of optimization. It demonstrates that carrier-selective contacts relying on non-Si materials are relevant for highefficiency silicon photovoltaics. As a perspective, reducing further the thickness of the $\mathrm{MoO}_{x}$ (based on Jsc trends, a 1-nm $\mathrm{MoO}_{\mathrm{x}}$-thick device should have a Jsc higher by $0.7 \mathrm{~mA} / \mathrm{cm}^{2}$ compared to actual 4-nm $\mathrm{MoO}_{\mathrm{x}}$-thick cells) layer and investigating the industrial feasibility and long term stability of such devices will be necessary steps before large-scale deployment of this technology can be envisaged.

\section{Acknowledgements}

The authors would like to thank C. Allebé and P. Wyss for the wafer cleaning and texturization, V. Paratte for processing passivation layers and electron contact on the c-Si wafer, $\mathrm{N}$. Badel for the Ag screen-printing metallization, and Cédric Bucher and Aymeric Schafflützel for technical support.

This project is funded by the Swiss national science fundation under Ambizione Energy Grant ICONS (PZENP2_173627).

[1] S. DeWolf, A. Descoeudres, Z. C. Holman, and C. Ballif, "High-efficiency silicon heterojunction solar cells: A review," Green, vol. 2, no. 1, pp. 7-24, 2012.

[2] C. Ballif et al., "Solving all bottlenecks for silicon heterojunction technology," Photovoltaics Internati, vol. 42, pp. 85-97, 2019.

[3] K. Yoshikawa et al., "Silicon heterojunction solar cell with interdigitated back contacts for a photoconversion efficiency over 26\%," Nat. Energy, vol. 2, no. 5, p. 17032, Mar. 2017.

[4] M. A. Green, E. D. Dunlop, D. H. Levi, J. Hohl-Ebinger, M. Yoshita, and A. W. Y. Ho-Baillie, "Solar cell efficiency tables (version 54)," Prog. Photovoltaics Res. Appl., vol. 27, no. 7, pp. 565-575, 2019.

[5] M. Tanaka et al., "Development of New a-Si/c-Si Heterojunction Solar Cells: ACJ-HIT (Artificially Constructed Junction-Heterojunction with Intrinsic Thin-Layer)," Jpn. J. Appl. Phys., vol. 31, no. Part 1, No. 11, pp. 3518-3522, Nov. 1992.

[6] M. Taguchi et al., "HITTM cells?high-efficiency crystalline Si cells with novel structure," Prog. Photovoltaics Res. Appl., vol. 8, no. 5, pp. 503-513, Sep. 2000.

[7] P. G. Le Comber and W. E. Spear, "Electronic transport in amorphous silicon films," Phys. Rev. Lett., vol. 25, no. 8, pp. 509-511, 1970.

[8] M. Bivour et al., "Doped layer optimization for silicon heterojunctions by injection-level-dependent 
open-circuit voltage measurements," IEEE J.

Photovoltaics, vol. 4, no. 2, pp. 566-574, 2014.

[9] A. Shah and W. Beyer, "BASIC PROPERTIES OF HYDROGENATED AMORPHOUS SILICON (\{a-Si:H\})," in Thin-Film Silicon Solar Cells, A. Shah, Ed. EPFL Press, 2010, pp. 17-96.

[10] W. G. J. H. . Van sark, F. Roca, and L. Korte, Physics and technology of amorphous-crystalline heteronstrutures sillicon solar cells. 2012.

[11] L. Zhao, C. L. Zhou, H. L. Li, H. W. Diao, and W. J. Wang, "Role of the work function of transparent conductive oxide on the performance of amorphous/crystalline silicon heterojunction solar cells studied by computer simulation," Phys. Status Solidi Appl. Mater. Sci., vol. 205, no. 5, pp. 12151221, 2008.

[12] E. Centurioni and D. lencinella, "Role of front contact work function on amorphous silicon/crystalline silicon heterojunction solar cell performance," IEEE Electron Device Lett., vol. 24, no. 3, pp. 177-179, 2003.

[13] M. Bivour, S. Schröer, and M. Hermle, "Numerical analysis of electrical TCO / a-Si:H(p) contact properties for silicon heterojunction solar cells," Energy Procedia, vol. 38, pp. 658-669, Jan. 2013.

[14] A. Paduthol, M. K. Juhl, G. Nogay, P. Löper, A. Ingenito, and T. Trupke, "Impact of different capping layers on carrier injection efficiency between amorphous and crystalline silicon measured using photoluminescence," Sol. Energy Mater. Sol. Cells, vol. 187, no. March, pp. 55-60, 2018.

[15] Z. C. Holman et al., "Current Losses at the Front of Silicon Heterounction Solar Cells," IEEE J.

Photovoltaics, vol. 2, no. No. 1, 2012.

[16] L. Mazzarella, S. Kirner, B. Stannowski, L. Korte, B. Rech, and R. Schlatmann, "P-type microcrystalline silicon oxide emitter for silicon heterojunction solar cells allowing current densities above $40 \mathrm{~mA} / \mathrm{cm} 2$," Appl. Phys. Lett., vol. 106, no. 2, pp. 0-5, 2015.

[17] L. Mazzarella et al., "Nanocrystalline silicon emitter optimization for $\mathrm{Si}-\mathrm{HJ}$ solar cells: Substrate selectivity and CO2 plasma treatment effect," Phys. Status Solidi Appl. Mater. Sci., 2017.

[18] A. N. Fioretti, M. Boccard, R. Monnard, and C. Ballif, "Low-Temperature \$ $p$ \$-Type Microcrystalline Silicon as Carrier Selective Contact for Silicon Heterojunction Solar Cells," IEEE J. Photovoltaics, 2019.

[19] D.-W. Kang, P. Sichanugrist, H. Zhang, and M. Konagai, "Wide-bandgap p-type microcrystalline silicon oxycarbide using additional trimethylboron for silicon heterojunction solar cells," Prog. Photovoltaics Res. Appl., vol. 15, no. February 2013, pp. 659-676, 2017.

[20] D. Zhang, D. Deligiannis, G. Papakonstantinou, R. van Swaaij, M. Zeman, and others, "Optical Enhancement of Silicon Heterojunction Solar Cells With Hydrogenated Amorphous Silicon Carbide Emitter," Photovoltaics, IEEE J., vol. 4, no. 6, pp. 1326-1330, 2014.

[21] J. P. Seif et al., "Amorphous silicon oxide window layers for high-efficiency silicon heterojunction solar cells," J. Appl. Phys., vol. 115, no. 2, p. 24502, 2014.
[22] C. Battaglia et al., "Hole Selective MoO," Nano Lett., vol. 14, pp. 967-971, 2014.

[23] M. Bivour, J. Temmler, H. Steinkemper, and M. Hermle, "Molybdenum and tungsten oxide: High work function wide band gap contact materials for hole selective contacts of silicon solar cells," Sol. Energy Mater. Sol. Cells, vol. 142, pp. 34-41, 2015.

[24] M. Mews, L. Korte, and B. Rech, "Oxygen vacancies in tungsten oxide and their influence on tungsten oxide/silicon heterojunction solar cells," Sol. Energy Mater. Sol. Cells, vol. 158, pp. 77-83, 2016.

[25] L. G. Gerling et al., "Transition metal oxides as holeselective contacts in silicon heterojunctions solar cells," Sol. Energy Mater. Sol. Cells, vol. 145, pp. 109-115, 2016.

[26] J. Meyer, S. Hamwi, M. Kröger, W. Kowalsky, T. Riedl, and A. Kahn, "Transition Metal Oxides for Organic Electronics: Energetics, Device Physics and Applications," Adv. Mater., vol. 24, no. 40, pp. 54085427, Oct. 2012.

[27] F. Menchini et al., "Transparent hole-collecting and buffer layers for heterojunction solar cells based on n-type-doped silicon," Appl. Phys. A, vol. 124, no. 7, p. 489, Jul. 2018.

[28] A. S. Gudovskikh et al., "n-GaP/p-Si Heterojunction Solar Cells Fabricated by PE-ALD," Phys. status solidi c, vol. 14, no. 10, Oct. 2017.

[29] J. Sheng et al., "Improvement of the SiO $x$ Passivation Layer for High-Efficiency Si/PEDOT:PSS Heterojunction Solar Cells," ACS Appl. Mater. Interfaces, vol. 6, no. 18, pp. 16027-16034, Sep. 2014.

[30] J. Geissbühler et al., "22.5\% Efficient Silicon Heterojunction Solar Cell With Molybdenum Oxide Hole Collector," Appl. Phys. Lett., vol. 107, no. 8, 2015.

[31] J. Bullock et al., "Stable Dopant-Free Asymmetric Heterocontact Silicon Solar Cells with Efficiencies above 20\%," ACS Energy Lett., vol. 3, no. 3, pp. 508513, Mar. 2018.

[32] W. Wu et al., "22\% efficient dopant-free interdigitated back contact silicon solar cells," in AIP Conference Proceedings, 2018, vol. 1999, no. 1, p. 40025.

[33] M. T. Greiner, M. G. Helander, W.-M. Tang, Z.-B. Wang, J. Qiu, and Z.-H. Lu, "Universal energy-level alignment of molecules on metal oxides," Nat. Mater., vol. 11, no. 1, pp. 76-81, Jan. 2012.

[34] C. Battaglia et al., "Silicon heterojunction solar cell with passivated hole selective MoO x contact," Appl. Phys. Lett., vol. 104, no. 11, p. 113902, 2014.

[35] J. Bullock et al., "E_cient silicon solar cells with dopant-free asymmetric heterocontacts," Nat. Energy, vol. 1, no. January, pp. 1-7, 2016.

[36] J. Meyer and A. L. Kahn, "Electronic structure of molybdenum-oxide films and associated charge injection mechanisms in organic devices," $J$. Photonics Energy, vol. 1, no. 1, p. 011109, Jan. 2011.

[37] M. Vasilopoulou et al., "The In $\mathrm{fl}$ uence of Hydrogenation and Oxygen Vacancies on Molybdenum Oxides Work Function and Gap States for Application in Organic Optoelectronics," 2012.

[38] A. Cuevas et al., "Carrier population control and 
surface passivation in solar cells," Sol. Energy Mater. Sol. Cells, vol. 184, pp. 38-47, Sep. 2018.

[39] C. Ballif, A. Descoeudres, M. Despeisse, and S. De Wolf, "Advances in crystalline silicon heterojunction research and opportunities for low manufacturing costs," 2015 IEEE 42nd Photovolt. Spec. Conf. PVSC 2015, pp. 1-5, 2015.

[40] D. Sacchetto et al., "ITO/MoOx/a-Si:H(i) HoleSelective Contacts for Silicon Heterojunction Solar Cells: Degradation Mechanisms and Cell Integration," IEEE J. Photovoltaics, vol. 7, no. 6, pp. 1584-1590, 2017.

[41] S. Essig et al., "Toward Annealing-Stable Molybdenum-Oxide-Based Hole-Selective Contacts For Silicon Photovoltaics," Sol. RRL, vol. 2, no. 4, p. 1700227, Feb. 2018.

[42] J. Werner et al., "Sputtered rear electrode with broadband transparency for perovskite solar cells," Sol. Energy Mater. Sol. Cells, vol. 141, 2015.

[43] J. H. Kim et al., "The effect of Ar plasma bombardment upon physical property of tungsten oxide thin film in inverted top-emitting organic lightemitting diodes," Org. Electron., vol. 12, no. 2, pp. 285-290, Feb. 2011.

[44] H. You, Y. Dai, Z. Zhang, and D. Ma, "Improved performances of organic light-emitting diodes with metal oxide as anode buffer," J. Appl. Phys., vol. 101, no. 2, p. 026105, Jan. 2007.

[45] I.-M. Chan and F. C. Hong, "Improved performance of the single-layer and double-layer organic light emitting diodes by nickel oxide coated indium tin oxide anode," Thin Solid Films, vol. 450, no. 2, pp. 304-311, Mar. 2004.

[46] B. A. Kamino et al., "Low-Temperature ScreenPrinted Metallization for the Scale-Up of TwoTerminal Perovskite-Silicon Tandems," ACS Appl. Energy Mater., p. acsaem.9b00502, May 2019.

[47] L. Lajaunie, F. Boucher, R. Dessapt, and P. Moreau, "Quantitative use of electron energy-loss spectroscopy Mo-M2,3 edges for the study of molybdenum oxides," Ultramicroscopy, vol. 149, pp. 1-8, 2015.

[48] H. Fujiwara and M. Kondo, "Effects of a-Si:H layer thicknesses on the performance of a-Si:H/c-Si heterojunction solar cells," J. Appl. Phys., vol. 101, no. 5, p. 054516, Mar. 2007.

[49] S. M. de Nicolás, D. Muñoz, A. S. Ozanne, N. Nguyen, and P. J. Ribeyron, "Optimisation of doped amorphous silicon layers applied to heterojunction solar cells," Energy Procedia, vol. 8, pp. 226-231, Jan. 2011.

[50] C. Battaglia et al., "Silicon heterojunction solar cell with passivated hole selective MoO x contact," Appl. Phys. Lett., vol. 104, no. 11, 2014.

[51] J. Bullock, A. Cuevas, T. Allen, and C. Battaglia, "Molybdenum oxide MoOx: A versatile hole contact for silicon solar cells," Appl. Phys. Lett., vol. 105, no. 23, 2014.

[52] C. Messmer, M. Bivour, J. Schön, S. W. Glunz, and M. Hermle, "Numerical Simulation of Silicon Heterojunction Solar Cells Featuring Metal Oxides as Carrier-Selective Contacts," leee J. Photovoltaics, vol. 1, no. 2, pp. 1-9, Mar. 2018.

[53] E. T. Roe, K. E. Egelhofer, and M. C. Lonergan, "Exchange current density model for the contactdetermined current-voltage behavior of solar cells," J. Appl. Phys., vol. 125, no. 22, 2019.

[54] J. Haschke et al., "Annealing of Silicon Heterojunction Solar Cells: Interplay of Solar Cell and Indium Tin Oxide Properties," IEEE J. Photovoltaics, vol. 9, no. 5, pp. 1202-1207, Sep. 2019.

[55] M. Boccard, C. Battaglia, F.-J. Haug, M. Despeisse, and C. Ballif, "Light trapping in solar cells: Analytical modeling," Appl. Phys. Lett., vol. 101, no. 15, p. 151105, 2012.

[56] J. Haschke, C. Messmer, J. Cattin, M. Bivour, M. Boccard, and C. Ballif, "Injection-dependent lateral resistance in front-junction solar cells with $\mathrm{nc}-\mathrm{Si}: \mathrm{H}$ and a-Si : $\mathrm{H}$ hole selective contact," in PVSC-46 Chicago, 2019. 